\title{
ManNer ANd Causation in Movement VerbS
}

\author{
Wilhelm Geuder \& Matthias Weisgerber, \\ Universität Konstanz / SFB 471
}

\{wilhelm.geuder | matthias.weisgerber\}@uni-konstanz.de

\begin{abstract}
This paper investigates the semantic underpinnings of the distinction between two syntactic types of "manner of movement" verbs in Levin (1993), namely the RUN and ROLL classes. According to Levin's (1993) and Levin \& Rappaport's (1995) work on unaccusativity, a semantic factor of "internal causation" should be the trigger for the classification of a movement verb as intransitive (=not-unaccusative), and hence for its belonging to the RUN class. We point out empirical problems for this characterisation, mainly coming from the different readings of the German verb fliegen (fly). From a comparison with other semantically similar verbs, we conclude that the semantic description which underlies the class distinction should be refined: instead of "internal causation", the crucial semantic factor is described here as "inherent specification for a momentum of movement". This result indicates that forces, and relations between forces, have to be part of the semantic description of the manner component in movement verbs.
\end{abstract}

\section{Introduction: Manner-of-Movement Verbs}

\subsection{A Syntactic Distinction}

A topic in verb semantics that has continued to attract attention is the distinction between two types of movement verbs, viz. "directed motion" vs. "manner of motion" verbs. In view of the large amount of literature devoted to this distinction, astonishingly few authors have addressed the issue of explicating the notion of "manner of movement", which lies at the bottom of this whole strand of research. One work which offers at least a subclassification of manner of movement verbs is Levin (1993). Levin notes a major contrast between two classes of manner of motion verbs, which she dubs the ROLL class and the RUN class. Here are some examples:

\begin{tabular}{|l|l|}
\hline run-class & roll-class \\
\hline $\begin{array}{l}\text { amble, climb, fly, jump, } \\
\text { tiptoe, ... }\end{array}$ & $\begin{array}{l}\text { drift, drop, float, revolve, } \\
\ldots\end{array}$ \\
\hline
\end{tabular}

This grouping first and foremost reflects a syntactic distinction and is therefore connected to verb semantics only in an indirect fashion. As amply discussed in Levin \& Rappaport (1995), the ROLL class consists of verbs whose single argument behaves as an underlying object, i.e. they are unaccusative verbs (even when occurring in isolation), while the RUN class, in contrast, consists of verbs which are intransitive in a strict sense $^{1}$, i.e., verbs with an underlying subject argument (even if these verbs may enter into unaccusative constructions when combined with directional PPs).

\footnotetext{
${ }^{1}$ We want to avoid the awkward terminological opposition "unaccusative" / "unergative", so the term "(strictly) intransitive" will be reserved here for verbs with an underlying subject, as opposed to unaccusative verbs; the cover term which we use for the larger class of verbs with one argument is "one-place verbs".
} 
An important test for this distinction in English are constructions with a resultative adjective. As a rule, an adjective that adds a resultant state to a process verb can only be predicated of a syntactic object, cf. (2a-b) below. True intransitive verbs may still appear in this construction, but then a dummy reflexive object has to be inserted, as in $(2 \mathrm{~b})$.

(2) a. John kicked the door open

b. The children ran themselves tired. / * The children ran tired.

c. The door ${ }_{i}$ rolled $\left[t_{i}\right]$ open

Example (2c) then shows how resultative constructions can be used as an unaccusative diagnostic: unaccusative verbs are a class of seemingly exceptional one-place verbs which may appear in this construction with just their sole argument and without dummy reflexive object. The reason is that the sole argument of an unaccusative verb counts as an object for the purpose of the predication rule. ${ }^{2}$

\subsection{Semantic Correlates}

Levin \& Rappaport (1995) have investigated the question as to the semantic triggers of unaccusativity in great detail. They propose a set of linking rules, whose interaction derives the difference between verbs with underlying objects and underlying subjects. Given that verbs of manner of movement do not intrinsically denote a change of state - which is the single most important factor that triggers unaccusativity - what is most important for us are their "immediate cause linking rule" and the "default linking rule".

Consider first the formulation of the "immediate cause" linking rule:

\section{Immediate Cause Linking Rule}

"The argument of a verb that denotes the immediate cause of the eventuality described by that verb is its external argument."

(Levin \& Rappaport (1995), p.135)

One-place verbs which assign such an immediate causer role to their only argument are therefore intransitive. It is important to sort out some fine points in the interpretation of this rule, however. As the authors stress, an immediate cause(r) is not the same as an agent or a participant that exerts control over a situation. For example, verbs like hiccup may describe involuntary actions, but the immediate cause of the situation still lies with the subject. The same is true for verbs of emission, like shine or stink, and for verbs which denote the maintenance of a position or configuration, like kneel. With respect to examples of this kind, the authors explain their concept of causation as follows:

\section{(Internal) Causation:}

“...The concept of internal causation subsumes agency. However, an internally caused verb need not be agentive ... For example, the verbs blush and tremble ... can ... be considered to describe internally caused eventualities, because these eventualities arise from internal properties of the arguments."

(Levin \& Rappaport (1995, p. 91))

The notion of "internal causation", which figures here is a subcase of the general concept of causation. If we are to apply the immediate causer rule to movement verbs, then internal causation is what is relevant for manner of movement verbs. In general, the notion of "internal causation" serves to separate verbs like the ones just discussed from "external causation" in which the causer is not involved in the manner of the event but merely sets

\footnotetext{
${ }^{2}$ For our purposes, it is not necessary to resolve the question of whether the unaccusativity tests really establish a difference in the syntactic position of the argument, or whether they are sensitive to a semantic classification of verbs. For ease of exposition, we adopt the syntactic parlance.
} 
things into motion. This latter class of verbs allows the causer to be dropped, giving rise to the causative-inchoative alternation, which occurs e.g. with roll:
a. They rolled the cheese to the train station
b. The cheese rolled to the train station

External causers can only appear with transitive verbs, because otherwise the remaining core of the situation (minus the causer) would not have a participant. One-place verbs therefore can only appear with internal causers, or be unaccusative, i.e. without causer at all. This leads us to an additional criterion that supports the classification of movement verbs: If there is a transitive variant with a meaning of direct causation - like (5a) above - the corresponding one-place variant was unaccusative, and hence belongs to the ROLL class.

When we are dealing with a member of the RUN class, there may sometimes be transitivecausative variants, too, but they invariably have a meaning of indirect causation. Since the lexical meaning already specifiies an internal causer, the addition of another causer subject in the transitive construction leads to a chaining of causes, i.e. a role of indirect causer for the highest argument, and a role of immediate causer for the other one. For example, in (6) below, the subject is an indirect causer because it is understood that it is still the rat itself that does the running:

(6) The psychologists ran the rat through the maze

Levin \& Rappaport (1995) point out that in such examples the directional PP is needed for the example to be grammatical. This seems to be related to the finding that addition of a directional PP creates a change in syntactic categorisation, turning any agentive movement verb into an unaccusative construction. In other words, there is a linking rule according to which a feature of directionality of movement triggers unaccusativity, and this rule overrides the causer rule (Levin \& Rappaport 1995, p. 158). Apparently, then, what happens is that a syntactically unaccusative structure is needed as a basis for causativisation to apply. The conceptual content of the verb's meaning is not lost, however, even if the directional PP creates a change in syntactic categorisation. Hence, the interpretation is that of indirect causation.

In sum, we can use causativisation patterns to diagnose a lexical verb as unaccusative, provided we make sure that the interpretation involves direct causation and that the derivation also works in the absence of a directional PP. Verbs of the RUN-class, in contrast, show a different causativisation pattern: causatives are confined to structures with directional PPs.

\subsection{Unaccusativity as Default}

There is one further component of Levin \& Rappaport's model that we need to take into account here:

\section{Default Linking Rule}

"An argument of a verb that does not fall under the scope of any of the other linking rules is its direct internal argument."

(Levin \& Rappaport (1995, p.154))

We need not be concerned with the question of which other linking rules there are - none of them would be relevant to the group of manner of movement verbs. But what is important is the default status of unaccusativity that follows for one-place verbs: if no particular semantic property is present that triggers linking of a verb's sole argument to the subject position (or object position), the single argument will be treated like an object. As a consequence, it would only be the RUN-class which carries a positive semantic specification for a feature "internal 
causation". In contrast, the unaccusative ROLL-class is an "elsewhere" case with no unified semantic definition.

In sum, then, the ROLL class emerges as a class of verbs which appears to be underspecified in two respects: these verbs do not provide a causer of the situation they describe, and they do not exhibit a positive specification that defines them as a unified semantic class. In contrast, RUN verbs are a type of manner of movement verbs which have a positive semantic specification (internal causer) that defines them as a unified class in terms of syntactic and semantic classification.

\section{The Problem of Double Classification}

We now want to discuss an apparent drawback of the classification of manner of movement verbs shown in (1) above, namely the fact that a large number of verbs is listed by Levin (1993) in both groups simultaneously. In other words, there appears to be a large amount of lexical variability with respect to the semantic factor that determines unaccusativity, and one might ask whether this blurring of the categories is a reason to doubt the lexical-semantic relevance of the grouping.

\begin{tabular}{|l|l|}
\hline RUN-class & ROLL-class \\
\hline amble, climb, fly, jump, & drift, drop, revolve, rotate, \\
float, glide, slide, roll (!), ... & float, glide, slide, roll, ... \\
\hline
\end{tabular}

The doubling of the entries in the second line of each cell points to the fact that certain verbs can be construed as internally caused movement or, alternatively, as movement brought about by an implicit external force. The resultative test confirms that these really belong to two separate classes:

a. The curtain rolled [ $(*$ itself $)$ open].

b. The children rolled [the grass flat].

(Levin \& Rappaport 1995: 209-10)

Example (9b) is understood as describing a volitional action by the children. The resultative construction displays the structure of intransitive verbs in that it allows an additional object that is not selected by the verb roll but case-marked by it. The appearance of a non-selected object is a phenomenon which is akin to the insertion of a dummy reflexive; unaccusative verbs are unable to support either type of object.

The reason for the fact that only some of the verbs but not all of them allow the alternation in (9) should obviously be sought in their lexical semantics. Levin \& Rappaport (1995: 211) state: "The variable behavior of certain verbs of manner of motion is simply the result of the existence of a lexical semantic constant that, by virtue of its nature, is basically compatible with more than one lexical semantic template." In other words, the manner component in the meaning of the verb roll is neutral with respect to the feature [ \pm internal causation], and so a feature of internal causation may be freely added. We take the quotation to mean that this difference in interpretation can be represented as the augmentation of a semantic template:

$$
\mathrm{x} \text { PROCESS }_{<\text {ROLL }>} \rightarrow \quad \mathrm{x} \text { PROCESS }<\text { ROLL }><\text { INTERNALLY CAUSED }>
$$

It may be noted that the variability of ROLL verbs only concerns causation while the manner of movement remains unchanged. Hence, this is not a case of lexical ambiguity, i.e. involving different lexical entries, but an instance of productive polysemy. The augmentation is only possible if the specification of a causer feature is absent from the semantic core of the verb, 
and this in turn is exactly a trigger of unaccusativity. Therefore, we conclude that the existence of these two variants is actually not an irregularity that threatens the semantic relevance of the classification, but rather on the contrary, it shows a hallmark of the ROLLclass, which is to be predicted from lexical semantics. We have to view the alternating verbs as ROLL verbs in their underlying form, with the proviso that they may acquire an additional semantic feature and switch to a grammatical realisation as an intransitive.

In this way, the phenomenon of double classification is a direct result of the semantically underspecified character of ROLL verbs noted in section 1.3 above. Note, incidentally that the class of unaccusatives again proves to be heterogeneous, because not all ROLL verbs are able to undergo the shift in (10). Hence, it is possible for a verb to belong to the ROLL class, and be unaccusative, not because it is unspecified with respect to causation, but because it is negatively specified wrt. the possibility of internal causation and so blocks the application of (10).

\section{The Problem of the Verb fliegen / fly}

\subsection{Variants: Conceptual Modulation}

In this section, we get to a problem that turns out to be the mirror image of the case discussed in section 2, namely a verb that should be expected to switch between classes but which doesn't. The German verb fliegen, and its English counterpart to fly display a range of uses that seems to replicate the distinction between internally caused and externally caused variants:

(11) a. Ein Vogel flog durch das Fenster

A bird flew through the window

b. Das Flugzeug flog durch die Wolken

The plane flew through the clouds

c. $\quad$ Ein Stein / Eine Gewehrkugel $\}$ flog durch das Fenster

\{A stone / A bullet\} flew through the window

In (11a) it is clear that the bird is an internal causer, since birds fly by moving their wings. For examples like (11b) it is hard to judge to which extent causation is internal (do we have to acknowledge the pilot of the plane as an external causer?), but it is clear that the plane is still generating the movement. (11c) behaves differently from (11a-b) since the bullet is known to have been fired from a gun - the bullet itself is not something that brought about the situation because of its intrinsic properties. In light of the preceding discussion, such examples are expected to class with the ROLL verbs. An example that clearly demonstrates that fly may describe situations with external causes is (12), where the context explicitly refers to one:

(12) He was shielding his head with his arms, and was hit by a large force of some kind. Nick flew through the window, shattering the glass, and ... ${ }^{3}$

In spite of all this, we are going to show that there are no indications that fliegen / fly may ever display unaccusative behaviour (in isolation). ${ }^{4}$ It can also be noted that fly is listed only

\footnotetext{
${ }^{3}$ quizilla.com/users/Sorrow1991/quizzes/Forever

${ }^{4}$ Remember that any kind of movement verb gives rise to an unaccusative construction when combined with directional PPs. Therefore, constructions with a directional PP have to be left out of consideration in our search for the correct lexical classification of the verb fliegen / fly.
} 
with the RUN class in Levin (1993), but in the detailed study of Levin \& Rappaport (1995) and in the other literature that we are aware of, there is no discussion on whether this classification is correct, and whether it is in need of explanation. So establishing and explaining the intransitive status of (11c) will be our central concern for the rest of this paper.

The unaccusative pattern of the resultative construction does appear with fly, it is true, but not in the sense of a movement verb:

(13) a. The machine flew to pieces

b. The door flew open

c. Old Nathan flew hot frequently, and the anger puffed away like flame from thistledown. But he was capable of cold rages also. ${ }^{5}$

Example (13a) could simply be about an explosion, it does not mean that pieces came off the machine as a result of flying in the air. Likewise, in (13b) there is no door flying through the air which becomes open as a result of that movement, and (13c) is a metaphorical extension that bears very little resemblance to the movement sense.

Whenever there is a sense of movement through the air, we rather get the intransitive pattern. Compare the unaccusative (13a) above with the intransitive pattern of the resultative in (14), which describes literal flying:

(14) The future looks grim My friends, if Nasa don't [...] start working on a new shuttle, one that doesn't fly itself to pieces. ${ }^{6}$

Also, we were unable to find German examples with the unaccusative pattern of the resultative construction. Most combinations of fliegen with a resultative adjective sound very marginal. One of the few clear examples ${ }^{7}$ is shown in (15) below: imagine an inflated balloon which is flying around as it is emitting the air inside. If, in the end, the balloon is empty, this would have to be expressed as in (15b), not as in (15a):
a. \# Der Luftballon ist leer geflogen ${ }^{8}$
The balloon has flown empty
b. Der Luftballon hat sich leer geflogen
The balloon has flown itself empty

Note, however, that this does probably still not count as a case of external causation, even though an agent is lacking. So we are still without a clear test to check the type (11c) above for unaccusativity.

\footnotetext{
${ }^{5}$ www.webscription.net/10.1125/ Baen/0671720848/0671720848___ 1.htm

${ }^{6} \mathrm{http}: / /$ blogorants.blogspot.com/

${ }^{7}$ Here is our second best attempt at a counterexample: In German you can have an unaccusative resultative construction with a polysemic variant of laufen / run:

(i) Der Pilot bemerkte, dass der Motor heiß lief.

The pilot noticed that the machine was running hot

Let us consider its somewhat magical counterpart in a fairy-tale world:

(ii) [Die Hexe, die den neuen Besen zum ersten mal flog, bemerkte, dass etwas nicht in Ordnung war: ] ? Der Besen flog heiß

[The witch, who was riding the new broom for the first time, noticed that something was wrong:] the broom flew hot

To the best of our judgement, example (ii) is syntactically not acceptable, but it is indeed hard to judge.

${ }^{8}$ A surface string like (15a) is syntactically acceptable but only on the irrelevant reading as an adjectival passive, not as a verbal construction with a perfect auxiliary. (15a) as an adjectival passive is the regular outcome of derivation from the verbal construction $(15 b)$.
} 
There is a second criterion that can be applied, namely causativisation. If fliegen / fly had an unaccusative variant (lacking internal causation), one might expect direct causatives. In the case of $f l y$, a direct causative would have to be similar to the meaning of "throw":

(16) * Er flog einen Stein durch mein Fenster

He flew a stone through my window

What we have to note with respect to this example is a divergence between German and English. The German sentence is clearly impossible with the intended interpretation. For the English version, we do have attestations, although they seem to be rare. Since the point is important, and tricky, we should consult our results from a web search:

(17) hi everyone, need to get a 3rd gen headlight have a hole in ours where a lorry flew a stone up and hit us (www.yotasurf-online.co.uk/ public/forums/showthread.php?p=90648)

(18) Will you fly a stone through my window like you used to do? (http://www.poetryvault.com/Display_Print.asp?ID=4729)

(19) Japan and the US began joint research into a next-generation missile defence system shortly after North Korea flew a missile over Japan in 1998. (http://news.bbc.co.uk/2/hi/asia-pacific/4104301.stm)

(20) Here's an accurate analogy of an [Toyota] MR2 being driven fast: It's like trying to fly an arrow backwards.

(http://www.hondaswap.com/forums/lofiversion/index.php/t46259.html)

(21) 'Cos You fly an arrow Straight to my heart Blow it apart...

(www.lyricshost.com/lyrics.php/

95274/Badly_Drawn_Boy_lyrics/Chaos_Theory_lyric)

When going through these examples, it seems hard to judge intuitively whether the semantics is one of direct causation of not. With respect to the example (19) involving a missile, indirect causation is most plausible, as the missile is moving by itself. More importantly, all examples involve a directional complement. This in fact aligns the examples with the derived causatives from agentive intransitive verbs that we introduced in section 1.2. There are very few exceptions with fly:

(22) It keeps hundreds, if not thousands, of people who can barely fly a paper dart rushing to your LHS to buy brightly coloured boxes covered in shrinkwrap and ... (www.wattflyer.com/forums/showthread.php?t=4400)

(23) Throw a piece of cardboard straight out like you were flying a paper plane. It will almost immediately fly at an upward angle (www.yale.edu/ynhti/curriculum/ units/1988/6/88.06.02.x.html)

It is possible, however, that single agentive verbs or even single collocations acquire a lexicalised causative variant; the same happens with walk the dog and run the dog, which do not generalise so as to yield ??The general walked the soldiers etc. Our impression is that the same is the case with the collocation fly a paper dart. A collocation fly an arrow, which would be closely analogous, could not be found in an internet search: from roughly 800 attestations of the string "fly an arrow" all relevant ones had as their larger context the construction "let fly an arrow" (with object extraposition). One may speculate that the use of "let" here even points to a conceptualisation of the situation as some kind of self-propelled movement (even though the flying of an arrow is clearly an instance of externally caused movement in terms of physics). 
So in sum, the behaviour of the verb fly exhibits close parallels to run: we have directionals in the productive causativisations, and the exception fly a paper dart is an idiosyncratic case which does not generalise.

Another observation can be made which points in the same direction: the causative uses of fly attested in (17) through (23) do not have counterparts in German. This seems remarkable in view of the fact that German fliegen otherwise exhibits almost exactly the same range of readings as fly. It reminds us of the fact, however, that German systematically disallows causative derivations of agentive movement verbs. The following sentences exemplify a pervasive pattern (the a.-sentences translate the German b.-sentences):

(24) a. The cheese rolled to the train station / They rolled the cheese to the train station

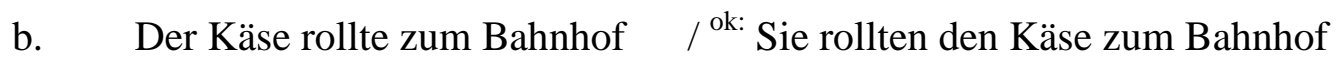

(25) a. The soldiers marched to the tent / The general marched the soldiers to the tent.

b. Die Soldaten marschierten zum Zelt

/ * Der General marschierte die Soldaten zum Zelt

In order to drive home this point, note that there are also some unaccusative verbs which block causative derivations, probably for reasons of their individual lexical semantics. For example, the verb rotate has a causative only in the sense of "turn something around an axis" (rotate the picture), but the use which involves movement along a trajectory (a planet rotates around a star) does not have a causative (with a hypothetical meaning like "insert into orbit"). This very subtle patterning of causative readings is exactly replicated by German rotieren and other German verbs of similar meaning. This parallelism is to be expected if the reason lies in some lexical semantic factor. Hence, the lack of a causativised variant of the movement verb fliegen in German is a highly significant indicator for its status as a RUN verb: it must be the pattern in (25) that we are dealing with.

We conclude that there are good reasons to believe that all uses of fliegen / fly as a movement verb pattern with the RUN-class, in spite of the fact that objects like arrows, bullets or stones are unable to act as internal causers of the movement.

\subsection{Polysemous Variants: Vehicle and Transport Readings}

There are more variants of the verb fliegen which may give some further indications as to its status as a movement verb. In this paper, we will not consider variants which we think belong to differenc conceptual domains, like a use which makes German fliegen near-synonymous to fall (Er flog in den Matsch "He fell into the mud"). What is of interest to us here is rather that there are more variants which denote a movement through the air: the German example (26) shows fliegen as a vehicle verb, and (27) as a transport verb (the range of usage in English is mostly parallel, though not entirely: many intransitive uses of fliegen in the vehicle reading would be translated as to pilot a plane). These two types are the only transitive-causative uses that German allows for fliegen:

(26) Er flog den Airbus nach Hamburg

He flew the Airbus to Hamburg

(27) Er flog die Eulen nach Athen

He flew the owls to Athens

The relevant interpretation of (26) is one in which the subject argument refers to the person who was piloting the airplane. In (27), we normally get the interpretation that the owls were carried as the load of a plane. Since the surface structure of the two sentences is the same, we 
get a number of additional interpretational possibilities that can be discarded only on the basis of reasoning from world knowledge, like the transport interpretation for (26) (but a jet will not normally be airfreighted in another one); or a kind of vehicle interpretation for (27) (but live birds would not normally do service as a mount; exceptions belong to the realm of fiction). Note also that no purely causative reading is available for (26) and (27), whether direct or indirect. Example (26), though, comes fairly close to being a causative, because piloting an airplane can be seen as indirect causation of a flying situation. Furthermore, the manner components in this use of the verb are exactly the same as in the intransitive movement variant The airbus was flying to Hamburg (compare also (11b)). Therefore, the vehicle variant can actually be said to involve the derivation of an indirect causative from the movement verb $f l y$ (even though there are other semantic differences along with this).

In sum, the absence of direct causatives in German that are based on flying as movement through the air, and the fact that some extensions of the underlying concept of movement through air display indirect causativity, is further support for the classification of the manner of movement verb fly as a RUN verb. This, however, is severely at odds with the impression that it has uses with external causation.

\section{Analysing the Meaning of fliegen /fly}

\subsection{Decomposing Causation}

As argued in section 2, the switch of some ROLL verbs to an interpretation with internal causer does not constitute an instance of deep lexical variation but is due to an underspecified slot in the lexical semantics of the verb. Notably, the manner of the movement, e.g. "rolling", does not change in this alternation. It could be argued that this is different with the variants of fliegen / fly shown in 3.1. At the very least, flying with the active use of one's wings, as birds do, seems to involve a different manner of movement than flying as of bullets. Therefore, it might be that we are dealing with real lexical polysemy in the case of fly. If the differences in manner point to lexical polysemy, the explanation of the different uses of fly would have to proceed in a way that is entirely different from the simple augmentation model that we sketched for ROLL. The variants of $f l y$ also give the intuitive impression that agentive flying is not to be described as an augmented variant of a pure manner of movement involving passive projectiles; since these are felt to be the more marginal variants, the connection should rather work the opposite way: the uses with inactive projectiles would somehow seem to constitute degenerated variants of the prototypical agentive case.

While this is all true, consideration of the manner differences does not really open up a way of analysing fly. One would need a full-blown model for a classification of manner of movement, which we can't accomplish in this paper (although we firmly believe that a calculus for explicating manner is a desideratum in current verb semantics). And to be sure, polysemy would multiply the problem of explaining the behaviour of the verb fly / fliegen, rather than solve it.

In the following, we rather want to show that the puzzle might be resolved by elaborating on the notion of "internal / external causation"; more precisely: by reinterpreting the relevant condition in terms of forces rather than causation. The various manners associated with the variants might then even be taken as belonging to a unified category.

Let us start our analysis with the observation that we must be dealing with more than a bivalent opposition [ \pm internal cause] in our examples, in view of the fact there are many intermediate cases to consider - like for instance: 
The problem is that in the middle range of this continuum, it is unclear to which extent causation should count as "internal". As a first step to clarify this, we propose to decompose the cause of the situation into two components, which may be dubbed Control and Force. The second refers to the source of the "energy" in the movement; the first is what guides the direction. The notion of control may be further split up into "intention of movement" (in a wide sense) or, alternatively, non-intentional factors that direct the movement. In our prototypical example (11a), all causal factors coincide in the subject argument, the bird. However, the other examples differ in the exact allocation of causal factors.

First, the examples differ in whether the source of energy lies with the subject of fly or not: animals and all kinds of aircraft with engines generate the movement's FORCE, and with respect to this they appear to be prototypical internal causers. Flying stones and the like do not localise the source of energy in the event of flying; here, it is known that this source must be external to this event, namely it must lie in some other prior event (cf. 12 above).

Similarly, the degree of CONTROL that can be attributed to the subject is decreasing over the items (28a) to (28d). This may mean that either, control devolves on some entity outside the scope of the event description (different types of "remote control" in (28b) and (28c)), or that it is an uncontrolled event. This is what must be posited for (28d). The pecularity of (28d) is that it is an event which must have an external origin of FORCE, but which nevertheless disallows external CONTROL. More precisely: while the generation of force (by the thrower) may be under control, the event of flying is not. Let us elaborate on this point via a comparison of fliegen with some related movement verbs.

\subsection{Verbs of Movement Through a Medium}

In this section we will elucidate the meaning of fly via a comparison with other verbs that denote movement of freely suspended objects: German schweben (float, hover), schwimmen (float [in water], swim), and fallen / fall.

German, as can be seen from these examples, does not make a distinction that seems systematically encoded in English: schwimmen refers to situations of active movement in water (swim) or passive movement or suspension in water (float). Likewise, schweben encompasses passive suspension in air (or water) (float) as well as situations in which an agent invests force to remain in a suspended position (hover). ${ }^{9}$ The relevant distinction is one in terms of the forces at play. In the illustrations below, we represent forces that are produced by the participant of the situation as curled arrows, and environmental forces as straight arrows. In a first approximation, this reflects a distinction between internal and external causation:

\footnotetext{
${ }^{9}$ Another piece of evidence for this lexical regularity (but of a different semantic type) is the pair bounce / jump, indiscriminately rendered as springen in German.
} 


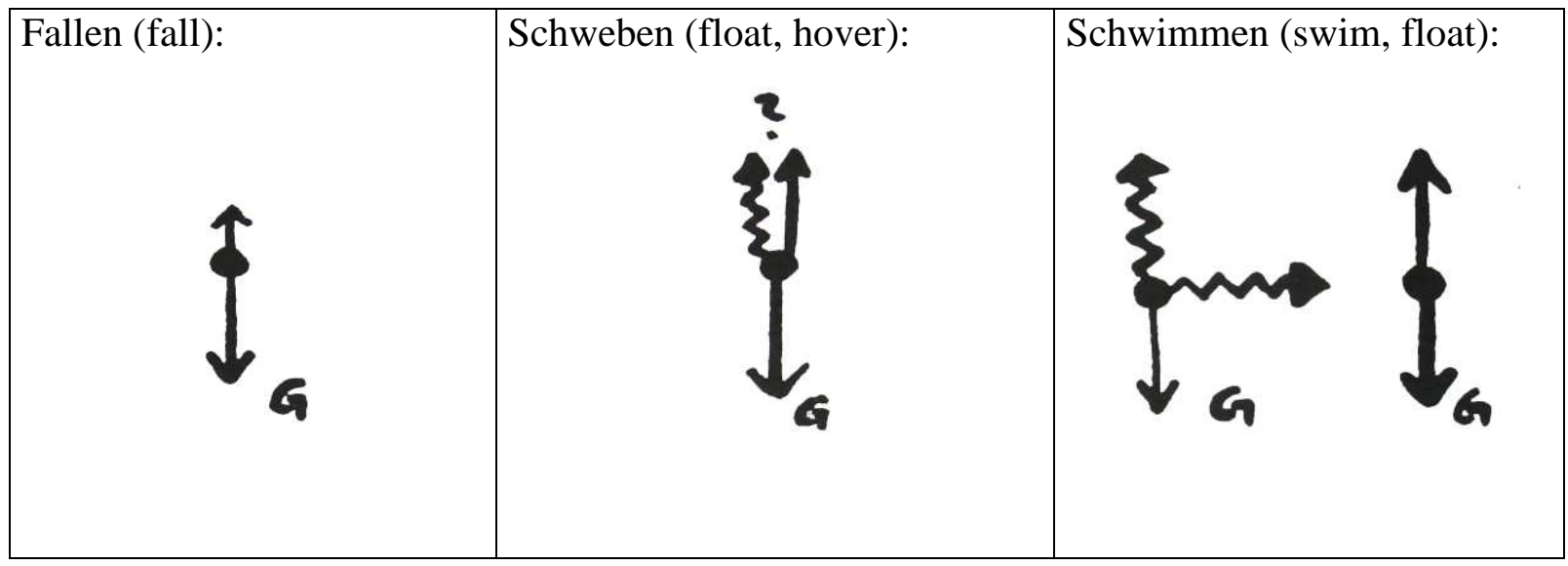

The external forces at play can be identified as gravitational and buoyant forces. In a situation of falling, a movement is created by gravitation, which at least outweighs bouancy. Schweben, is depicted in (30) with two upward arrows which are to be understood as alternative, i.e. as underspecified wrt their quality; choosing the curly force arrow would represent hover, the straight arrow float, because the latter relies on the environmental force of buoyancy. Schwimmen, on one reading, is represented via two force components, which secure staying at the surface and locomotion, respectively; the constellation to the right is an alternative interpretation for the German word, which would then correspond to float.

It might be expected that fliegen / fly should exhibit the same variability between selfpropelled motion and motion caused by environmental forces. If so, however, there would be an irregularity in that English does not make the lexical distinction which it makes in the cases swim/float and hover/float. A second peculiarity is that float is unspecified as to whether there is movement or not, while in contrast, fliegen has no interpretation with the object being at rest.
a. $\quad$ Eine Feder flog durchs Fenster
A feather flew through the window
b. Eine Feder schwebte in der Luft
A feather floated in the air
c. \# Eine Feder flog in der Luft
A feather flew in the air

Example (32c) needs careful analysis: it is acceptable on the interpretation that a feather is flying past, with unspecified direction. However, it does not allow a stationary reading (with, say, the feather being supported in a more or less stationary position by small turbulences in the air; this would not yield a movement path).

We believe that there is good reason why fliegen / fly does not alternate with a stationary interpretation in the same way as other verbs do, like schwimmen, schweben. There is no stable position with fliegen for a reason that is rooted in the very physics of flying: in this special case, the support is created by the motion itself. In other words, fliegen / flying is a situation in which an object carries a momentum of movement that prevents it from going straight downwards. 
Thus we claim that the relevant distinction between fliegen and schweben (float) is to be represented as a lexical specification for a movement with an intrinsic momentum. ${ }^{10}$ Schweben / float, in contrast, is a verb that describes an equilibrium of buoyancy and gravitational forces; movement is extrinsic to this description and can be freely added. The difference can be illustrated as follows - note that the curly arrows now have to be reinterpreted as referring to inherent as opposed to environmental forces. The momentum, depicted in (33) by a diagonal arrow, can be decomposed into two components, upward and forward, in keeping with the observation mentioned above that flying is a situation in which it is the movement which creates a support vector.

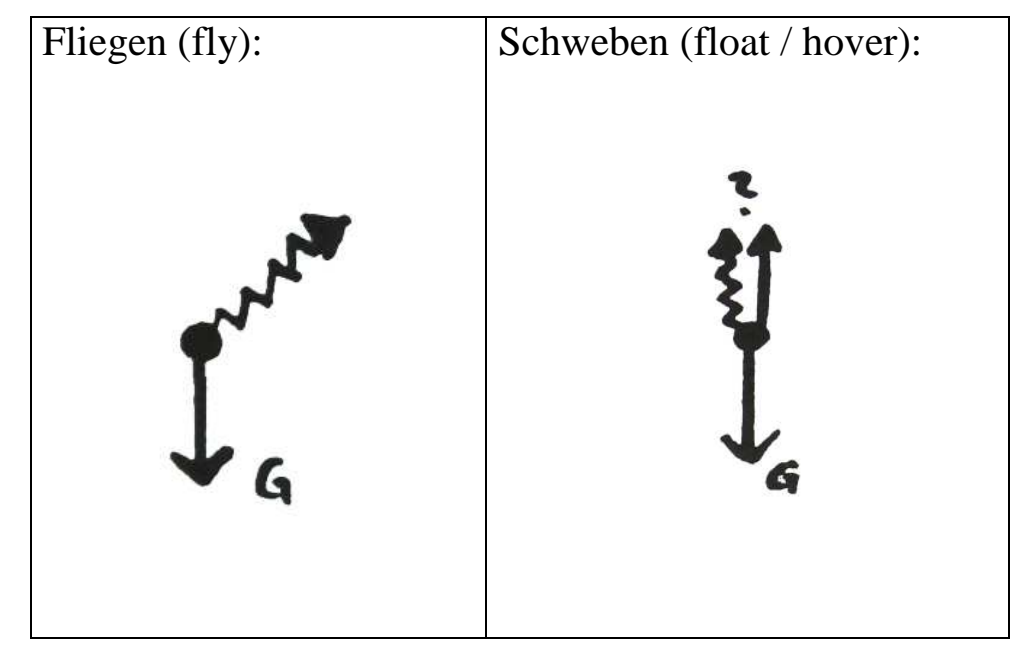

\subsection{Conclusion}

If our analysis is correct that fliegen requires its participant to carry a momentum of movement, this aligns it with the RUN-class in some sense: it is a factor intrinsic to the participant and to the situation. On the other hand, however, this factor is not the causation of the movement, which must be acknowledged as external in the case of flying stones etc. Therefore, we believe that the crucial semantic factor that distinguishes the RUN-class is not agentivity (even though this class is usually listed under "agentive verbs of manner of motion" even in Levin \& Rappaport 1995), nor is it situation-internal cause of the movement. Rather, it has to be inherent specification of a momentum of movement.

An observation which supports this conclusion is that the RUN verbs listed in Levin \& Rappaport (1995) in general disallow readings in terms of stationary support or passive movement by environmental forces, as far as we can determine. This is even true for the case of hover (which a reviewer mentioned as a potential counterexample). The verb hover specifies the exertion of a force in vertical direction which balances gravitation, and so this is another type of intrinsic force specification. It is true that hover behaves like float with respect to sideward movements, i.e. it is neutral as to whether they occur or not and leaves this to environmental forces; but this parallelism is only due to the fact that hover specifies a momentum of force only in one spatial dimension. The verb float also describes an equilibrium between two vertical forces (gravitation and buoyancy), but this is an equilibrium of external, environmental forces. A stone or arrow inherits a momentum of movement from

\footnotetext{
${ }^{10}$ The use of German fliegen in a sense similar to fall mentioned at the beginning of section 3.2 still reflects this, as the interpretation seems to be a falling with a forceful component. However, we continue to assume that it is a separate lexical variant that is connected via a similarity link to the sense of movement through air
} 
the external force which launched it, and then carries it as its own intrinsic property; as soon as the projectile is flying, it is no longer under external control with respect to this property.

Many situations that may be described by words like roll, spin, etc. are situations in which an object likewise has inherited a momentum of movement. This, however, is merely a fact about the situation, it is not part of the property expressed by the verb. The property denoted by these verbs rather lies in the domain of shape or directionality properties of the movement. By virtue of their not carrying any intrinsic specification concerning momentum of movement, they are classed as unaccusative.

\section{Acknowledgement}

This work was written with support from the SFB 471 "Variation and Evolution in the Lexicon", funded by the Deutsche Forschungsgemeinschaft.

\section{References}

Levin, B.: 1993, English Verb Classes and Alternations. Chicago: Univ. of Chicago Press.

Levin, B. \& Rappaport Hovav, M.: 1995, Unaccusativity. Cambridge MA: MIT Press. 